University of Massachusetts Amherst

ScholarWorks@UMass Amherst

Chemical Engineering Faculty Publication

Series

Chemical Engineering

2019

\title{
Biomechanical microenvironment regulates fusogenicity of breast cancer cells
}

\author{
Peiran Zhu \\ Ning-Hsuan Tseng \\ University of Massachusetts Amherst \\ Tianfa Xie \\ University of Massachusetts Amherst \\ Ningwei Li \\ University of Massachusetts Amherst \\ Isaac Fitts-Sprague \\ University of Massachusetts Amherst
}

See next page for additional authors

Follow this and additional works at: https://scholarworks.umass.edu/che_faculty_pubs

\section{Recommended Citation}

Zhu, Peiran; Tseng, Ning-Hsuan; Xie, Tianfa; Li, Ningwei; Fitts-Sprague, Isaac; Peyton, Shelly; and Sun, Yubing, "Biomechanical microenvironment regulates fusogenicity of breast cancer cells" (2019). ACS Biomaterials Science \& Engineering. 876.

https://doi.org/10.1021/acsbiomaterials.8b00861

This Article is brought to you for free and open access by the Chemical Engineering at ScholarWorks@UMass Amherst. It has been accepted for inclusion in Chemical Engineering Faculty Publication Series by an authorized administrator of ScholarWorks@UMass Amherst. For more information, please contact scholarworks@library.umass.edu. 


\section{Authors}

Peiran Zhu, Ning-Hsuan Tseng, Tianfa Xie, Ningwei Li, Isaac Fitts-Sprague, Shelly Peyton, and Yubing Sun 


\section{Biomechanical microenvironment regulates fusogenicity of breast cancer cells}

Peiran Zhu ${ }^{1}$, Ning-Hsuan Tseng ${ }^{2}$, Tianfa Xie ${ }^{1}$, Ningwei Li ${ }^{1}$, Isaac Fitts-Sprague ${ }^{1}$, Shelly R. Peyton $^{2,3,4}$, and Yubing Sun $1,2,3,4^{*}$

${ }^{1}$ Department of Mechanical and Industrial Engineering, University of Massachusetts, Amherst, Massachusetts 01003, USA.

${ }^{2}$ Molecular and Cellular Biology Graduate Program, University of Massachusetts, Amherst, Massachusetts 01003, USA.

${ }^{3}$ Department of Chemical Engineering, University of Massachusetts, Amherst, Massachusetts 01003, USA.

${ }^{4}$ Institue for Applied Life Sciences, University of Massachusetts, Amherst, Massachusetts 01003, USA.

\section{KEYWORDS}

Breast cancer, cell fusion, micropattern, matrix stiffness, curvature, mechanotransduction

\section{Corresponding Author}

${ }^{*}$ Correspondence should be addressed to Y. Sun (ybsun@umass.edu) 


\begin{abstract}
Fusion of cancer cells is thought to contribute to tumor development and drug resistance. The low frequency of cell fusion events and the instability of fused cells have hindered our ability to understand the molecular mechanisms that govern cell fusion. We have demonstrated that several breast cancer cell lines can fuse into multinucleated giant cells in vitro, and the initiation and longevity of fused cells can be regulated solely by biophysical factors. Dynamically tuning the adhesive area of the patterned substrates, reducing cytoskeletal tensions pharmacologically, altering matrix stiffness, and modulating pattern curvature all supported the spontaneous fusion and stability of these multinucleated giant cells. These observations highlight that the biomechanical microenvironment of cancer cells, including the matrix rigidity and interfacial curvature, can directly modulate their fusogenicity, an unexplored mechanism through which biophysical cues regulate tumor progression.
\end{abstract}




\section{INTRODUCTION}

Multinucleated giant cells (MGCs) have been frequently found in cultured cancer cell lines, animal models, and solid tumors in humans ${ }^{1-5}$. Recent findings suggest that MGCs are highly tumorigenic, more drug resistant, and more metastatic relative to non-MGCs in the same tumor ${ }^{4}$, 6-7. Spontaneously fused bone- and lung-tropic variants of the MDA-MB-231 human breast cancer cell line can acquire dual metastasis organotropism ${ }^{8}$. Despite the importance of MGCs in tumor biology, the regulatory mechanisms of their formation and maintenance are poorly understood $^{9}$. Cell-cell fusion also occurs spontaneously in several normal developmental processes including fertilization, muscle development, bone remodeling, and macrophagemediated immunoresponses ${ }^{10-12}$. Activation of ELMO/Dock180/Rac1 signaling has been shown to be involved in the fusion of myoblasts and macrophages ${ }^{10,13-14}$. Recently, it has been found that Rho-myosin activities are required for the fusion of myoblasts ${ }^{15}$. While these results strongly suggest the connection between biomechanical cues and cell fusion, it has not been examined in cancer cell fusion.

Growing evidence is proving that the biophysical properties of cancer cells and cancer microenvironment play a critical role in regulating tumor growth and metastasis ${ }^{16}$. For example, the tumor extracellular matrix (ECM) is notoriously stiff relative to healthy tissue ${ }^{17-22}$, which is associated with extensive changes in biochemistry ${ }^{23-25}$ and metastatic potential ${ }^{26-29}$. During the growth of a tumor, the ECM shifts from one rich in basement membrane proteins to one dominated by collagen, and these collagen fibers are reorganized by cancer-associated fibroblasts (CAFs) into large, aligned, rigid fibers. This ECM turnover is coincident with metastasis in $v_{i v o}{ }^{30}$ and cell migration via ROCK signaling in vitro ${ }^{31-32}$. In addition, the interfaces between tumor and stroma also contribute to the tumor heterogeneity and progression, and the 
geometrical confinement causes variation in the mechanical stresses within tissues, suggesting the need of mimicking the confined tumor structure ${ }^{33-35}$. For instance, by micropatterning cancer cells in 2D and 3D matrices, Kilian and colleagues discovered that the interfacial geometry strongly influenced the cancer cell tumorgenicity ${ }^{36}$. Together, these findings highlight the importance of biophysical cues in regulating the behavior of tumor cells.

In this work, we discovered that biophysical cues from the microenvironment regulate the initiation and maintenance of breast cancer MGCs formed through spontaneous fusion. Biophysical cues in cancer microenvironment, including interfacial geometry ${ }^{36}$, matrix stiffness $^{20,37-38}$, and mechanical forces ${ }^{39-40}$, are known to be indispensable factors that regulate cancer cell behaviors, and this is the first report that these same biophysical factors can control the formation and fate of MGCs. When maintaining cells at an optimal density (approximately 1000 cell $\cdot \mathrm{mm}^{-2}$ ) using a microfabricated dynamic cell patterning platform, MGCs are sustained and can proliferate. We further depicted that such cell fusion process can be tuned by matrix rigidity, cytoskeletal tension, and pattern curvature, and reduced intracellular forces facilitate the maintenance of MGCs. Our results suggest that cell fusion might occur more frequently than previously thought, and soft tumor tissues can facilitate the formation and stabilization of MGCs with high tumorigenic potentials.

\section{MATERIALS AND METHODS}

Cell culture: In our experiments, we used three representative breast cancer cell lines with different E-cadherin expression levels: BT549, HCC1806, and MCF7. The breast cancer cell line HCC1806 was generously provided by Dr. Mario Niepel at the Harvard Medical School and 
human breast cancer cell lines BT549 and MCF7 were generous gifts from Dr. Shannon Hughes at the Massachusetts Institute of Technology. HCC1806 and BT549 cells were grown in Roswell Park Memorial Institute (RPMI; 11875-085, Life Technologies) supplemented by 10\% FBS (Life Technologies) with penicillin/streptomycin (Gibco) in T25/T75 flasks. Cells were cultured at $37^{\circ} \mathrm{C}$ and with $5 \% \mathrm{CO}_{2}$. For the experiments shown in Figure 2e, to make HCC1806 cell subclones, cells were grown in RPMI with $10 \%$ FBS and plated at the density of 1 cell/well in 96-well plates. Replenish cell culture media every 2-3 days. Subclones were expanded from 96well plates to 12 -well plates, 6-well plates and eventually $10-\mathrm{cm}$ dish. Plate transfers were only performed when the cells were confluent. One of these subclones was randomly selected for our study. MCF7 cells were cultured in Dulbecco's Modified Eagle Medium (DMEM; 11320-082, Life Technologies) with $10 \%$ FBS, $1 \%$ penicillin/streptomycin. Media were changed every three days, and cells were passaged when they were nearly $90 \%$ confluent using $0.25 \%$ trypsin-EDTA (Gibco).

Microcontact printing: To control the cell density and track the cell fate using live-cell imaging conveniently, we used soft lithography and microcontact printing techniques to generate fixed patterns, as described previously ${ }^{41}$. Briefly, patterned PDMS stamps were molded from negative SU8 molds that were fabricated using photolithography. Round glass coverslips with a diameter of $18 \mathrm{~mm}$ (Fisher Scientific) were spin coated (Spin Coater; Laurell Technologies) with a thin layer of PDMS prepolymer containing PDMS base monomers and curing agents (10:1 w/w; Sylgard 184, Dow-Corning) before the PDMS layer was thermally cured by baking at $110^{\circ} \mathrm{C}$ for at least $24 \mathrm{hr}$. In parallel, PDMS stamps were soaked in fibronectin solution $\left(50 \mu \mathrm{g} \cdot \mathrm{ml}^{-1}\right.$ in sterile, deionized water) for $1 \mathrm{hr}$. Excess fibronectin was then washed away by DI water, and the stamps were dried with a stream of $\mathrm{N}_{2}$. Fibronectin coated stamps were gently placed on the top 
of the flat PDMS substrates, after treating with UV ozone for $7 \mathrm{~min}$. The stamps were pressed gently to facilitate the transfer of fibronectin to coverslips. Protein adsorption to all PDMS surfaces not coated with fibronectin was prevented by immersing coverslips in a cell-culture grade $0.2 \%$ Pluronics F127 NF solution (Sigma) for 30 min. Coverslips were rinsed with PBS and transferred to standard 12-well tissue culture plates for seeding cells.

Dynamic patterning: To allow free expansion of cells after initial patterning, we used a PDMS membrane with through holes as stencils covering a flat PDMS substrate to allow initial confinement of cells before the membrane was released to allow the outgrowth of cells ${ }^{42}$. PDMS membranes with a thickness between $50-100 \mu$ m were first generated by spin coating. Next, an array of through-holes was generated on PDMS membranes using a biopsy puncher (Outer Diameter $=1000 \mu \mathrm{m})$. In parallel, PDMS coated coverslips were oxidized with UV ozone and coated with fibronectin $\left(50 \mu \mathrm{g} \cdot \mathrm{ml}^{-1}\right)$. PDMS stencils were then firmly adhered to the substrates, and 5-10 $\mu$ l of cells (loading concentration: $1 \times 10^{6}$ cell $\cdot \mathrm{ml}^{-1}$ ) were directly loaded into each hole to achieve the desired seeding density. Cells were incubated for $1 \mathrm{hr}$ at $37^{\circ} \mathrm{C}$ and with $5 \% \mathrm{CO}_{2}$. Then, remaining media together with unattached cells were removed before releasing the stencils from substrates. Sufficient media were then added for long time culture.

F-actin staining: To visualize the cell shape, we immunostained F-actin in cells with Phalloidin (A12379, Alexa Fluor 488 Phalloidin, 1:40) according to the manufacturer's instructions.

Ki-67 staining: To investigate whether MGCs are capable of proliferating, we used Ki-67 to stain the cells. Samples were rinsed three times with PBS, fixed with $4 \%$ paraformaldehyde, permeabilized with Tris-buffered saline (TBS) containing 0.5\% Triton X-100 (Promega), and blocked with AbDil (2wt\% bovine serum albumin (BSA) in TBS with $0.1 \%$ Triton X-100, TBS- 
T). Samples were incubated for $2 \mathrm{hr}$ at room temperature with the primary antibody (Abcam, ab1667, 1:200), washed, and incubated with goat anti-Rabbit $\operatorname{IgG}(\mathrm{H}+\mathrm{L})$ secondary antibody for $2 \mathrm{hr}$ (Alexa Fluor 555, 1:500). Cells were counterstained with DAPI (Thermo, 1:1000) for $5 \mathrm{~min}$.

Cell-Tracker Assay: Two dishes of HCC1806 cells were stained with Cell-Tracker Green (C7025, Life Technologies) and Cell-Tracker Red (C34552, Life Technologies) following the manufacturer's instructions, respectively. Labeled cells were then dissociated into single cells. After counting, an equal number of cells from each group were evenly mixed together and seeded on patterned substrates (seeding concentration: $2 \times 10^{5} \mathrm{cell} \cdot \mathrm{ml}^{-1}$ ) and incubated for $1 \mathrm{hr}$. After cell attachment, fresh media were added for long-term culture. To estimate the percentage of cell fusion among all the MGCs in the total population, we assume the probability for cell fusion is not affected by fluorescent dyes labeling. Thus, the percentage of cell fusion equals three times (3x) the percentage of cells labeled with both colors. In this assay, we only counted MGCs with more than two nuclei to exclude the cells in G2/M phases of the cell cycle.

Live cell imaging: Time-lapse video-microscopy was performed by Cytation 3 Cell Imaging Multi-Mode Reader (BioTek). Cells were cultured in patterned (radius $r=200 \mu \mathrm{m}$ ) $35 \mathrm{~mm}$ glass bottom dishes at $37^{\circ} \mathrm{C}$ and with $5 \% \mathrm{CO}_{2}$. Cells were imaged $1 \mathrm{hr}$ after cell seeding. Images were obtained every 5,10 , or $15 \mathrm{~min}$ for the indicated time courses.

Image analysis: Phase and fluorescence images were recorded using an inverted epifluorescence microscope (Leica DMi8; Leica Microsystems) equipped with a monochrome charge-coupled device (CCD) camera. ImageJ (NIH, Bethesda, MD) was used for the measurement of the area of MGCs and mononuclear cells and compiling individual staining images. Confocal images were recorded using Nikon A1 Resonant Scanning Confocal with TIRF Module. Number of MGCs 
was counted manually based on the number of nuclei and cell size. To generate the colorimetric maps showing the distribution of MGCs in Figure 5, at least 50 images were analyzed for each pattern geometry. MGCs were marked in each image, and their coordinates were recorded. Each geometry was then divided into a $20 \times 20$ grid, and the amount of marked MGCs in each grid from all the images was then averaged. The matrix was then imported to OriginPro (OriginLab, Northampton, MA) to plot the colorimetric map.

Traction force microscopy: To characterize the mechanical forces exerted by normal cells and MGCs, we performed traction force measurement using PDMS micropost arrays (PMAs) as described previously ${ }^{43}$. Briefly, PMAs were first patterned for cell attachment using microcontact printing to uniformly coat micropost top surfaces with fibronectin (pattern radius, $r$ $=500 \mu \mathrm{m})$. PMAs were labeled with DiI (5 $\mu \mathrm{g} \mathrm{ml}^{-1}$; Life Technologies $)$ in distilled water for 1 hr. After microcontact printing, protein adsorption to all PDMS surfaces not coated with fibronectin was prevented by incubating in 0.2\% Pluronics F127 NF solution (Sigma) for 30 min. Images of micropost tops were recorded using a $40 \times$ objective (Leica DMi8). All images were recorded at day 1 and were analyzed using a custom-developed MATLAB program (MathWorks), as described previously ${ }^{44}$, to obtain traction force maps associated with each image.

Pharmacological treatment: Cell fusion process can be tuned by changing cell-cell interactions via EGTA treatment, which is a calcium chelator that can disrupt cadherin functions. For EGTA treatment, a stock solution of EGTA (10 mM, Sigma) was prepared by dissolving EGTA in water and adjusting $\mathrm{pH}$ with $\mathrm{NaOH}$ and $\mathrm{HCl}$. The stock solution was diluted in culture media to different concentrations (control, $0.1 \mu \mathrm{M}$, and $0.15 \mu \mathrm{M}$ ), and cells were treated $1 \mathrm{hr}$ after cell seeding. The number of MGCs were calculated after 4, 14, 26, and $47 \mathrm{hr}$ treatment, respectively. 
In addition, the cell fusion can also be affected by tuning contractile forces of cells. ROCK Inhibitor Y27632 can reduce the contractile forces, while lysophosphatidic acid (LPA) can activate ROCK signals and increase contractile forces. For Y27632 (Cayman Chemical, Ann Arbor, MI) treatment, a stock solution (10 mM in DMSO) was prepared and diluted in culture media to $10 \mu \mathrm{M}$. Cells were treated $1 \mathrm{hr}$ after cell seeding. For LPA (Invitrogen) treatment, a stock solution (10 $\mathrm{mM}$ in DMSO) was prepared and diluted in culture media to $10 \mu \mathrm{M}$. Cells were treated $1 \mathrm{hr}$ after cell seeding.

Statistics: Statistical analysis was performed using GraphPad Prism. For statistical comparations between two data sets, P-values were calculated using the student t-test function. For statistical comparations between three or more data sets, $\mathrm{P}$-values were calculated using the one-way ANOVA with Tukey post-hoc analysis.

\section{RESULTS}

\section{Cell fusion dictates the formation of MGCs on patterned substrates}

To conveniently monitor MGCs using live-cell imaging, we adopted a standard microcontact printing technique to confine breast cancer cells on patterned islands of extracellular matrix (ECM) proteins ${ }^{41,45}$. We cultured the breast cancer cell line HCC1806 on patterned surfaces and consistently observed MGCs within $1 \mathrm{hr}$ after cell seeding. Phalloidin and DAPI staining images showed that MGCs typically contained 2-5 nuclei (Figure 1a) and were about 6-fold larger than typical mononuclear cells (Figure 1b) in this assay. The size of MGCs linearly correlated with the number of cell nuclei (Figure 1c). Importantly, the confined environment introduced by patterning is not required for the formation of MGCs, as MGCs can also be observed in cells 
cultured on unpatterned glass substrates (Figure S1). The capability to proliferate is frequently observed in multinucleated cancer cells. We thus immunostained Ki-67 to examine whether MGCs have the capability to proliferate. As shown in Figure 1d, most MGCs are positive for Ki-67, suggesting that these cells are not growth arrested. Live cell imaging also revealed instances of an MGC dividing into two or even three MGCs (Figure S2). While such multipolar mitosis often leads to aneuploidy and cell death ${ }^{46}$, it appeared that these daughter cells were able to survive for at least $7 \mathrm{hr}$ as shown in Video S1 (from $58 \mathrm{hr} 26 \mathrm{~min}$ to $65 \mathrm{hr} 31 \mathrm{~min}$ ).

Cytokinesis failure from gene alternation, entosis, endoreplication, and cell fusion have been discovered as major pathways that lead to multinucleation ${ }^{47-48}$. We did not observe cytoskeletal structures outlining an intact cell within MGCs, indicating that entosis is unlikely involved (see Discussion). To elucidate the formation mechanism of MGCs in this assay, we first performed live cell video-microscopy to track the fate of cells between 1 and $66 \mathrm{hr}$ after cell seeding. We found that all the MGCs identified were formed due to fusions of mononuclear cells (Figure 1e). To further confirm that cell fusion is the major mechanism for MGCs formation, we labeled an equal amount of HCC1806 cells with cell-tracker green and cell-tracker red, and evenly mixed labeled cells together before plating on patterned surfaces. We found that $27.6 \%$ of MGCs displayed both green and red fluorescence, indicating they were formed from cell fusion, rather than cytokinesis failure (Figure 1f-g, Figure S3). As the probability for cells labeled with either green or red dyes to fuse should be the same, we estimated $82 \%$ of MGCs were formed due to cell fusion (see Methods for details). Notably, some ( 0.46\% of the total cell population) MGCs may already exist in the cell line, as we found several large cells when counting cells detached directly from flasks using a hemocytometer (Figure S4). However, as cells stained for both colors can only result from cell fusion, the pre-existing MGCs should not significantly affect our 
estimation, and may partially explain the observation that the percentages of MGCs displayed only red or green fluorescence were higher than those displayed both.

\section{Characterizing the behaviors of MGCs}

In our live-cell video microscopy experiments, we tracked MGCs for a long-term and found several features of them. First, in contrast to some drug-induced polyploid cancer cells ${ }^{6}$, MGCs are highly unstable. As depicted in Video S1 and Figure S5, which showed the entire process of the formation, division, and death of MGCs by tracking cells on the same pattern, most of MGCs rounded up and showed membrane blebbing before detaching the substrates within $36 \mathrm{hr}$. As mentioned previously, MGCs have the capability to divide into multiple MGCs (Figure 1d, Figure S2, and Figure S5b). However, some MGCs failed to complete cytokinesis (Figure S5c). Furthermore, we also observed that two MGCs could fuse into one cell (Figure S6). The majority of MGCs have two (42.4\%) to three (33.7\%) nuclei, suggesting that multiple fusion events exist but happen less frequently or result in unstable cells.

\section{Cell packing density regulate the fusogenicity of breast cancer cells}

We next sought to investigate the factors that regulate the fusogenicity of breast cancer cells by live imaging patterned cells (Figure S7). The percentages of MGCs were quantified based on the number of nuclei and cell size unless stated otherwise. Cells with more than one nucleus were counted as MGCs. We found that MGCs appeared as early as 1 hour after cell seeding, constituting $<1 \%$ of the total cell population, which is consistent with the reported number found in tumors ${ }^{4}$ (Figure 2a-c). We found that plating cells at a higher concentration $\left(6 \times 10^{5}\right.$ cells $/ \mathrm{ml}$ ) significantly increased both the total number and percentage of MGCs within the first hour, which strongly suggests that the formation of MGCs is facilitated at a high cell packing 
density. The level of cell-cell contact increased significantly with plating density. When plated at $3 \times 10^{5}$ cells $/ \mathrm{ml}, 40.1 \% \pm 5.9 \%$ of cells were in contact with other cells $1 \mathrm{hr}$ after cell seeding, while at $6 \times 10^{5} \mathrm{cells} / \mathrm{ml}$, this percentage increased to $75.3 \% \pm 7.5 \%$. Interestingly, we also found that the number and percentage of MGCs dropped faster when cells were plated at a higher concentration $\left(6 \times 10^{5}\right.$ cells $\left./ \mathrm{ml}\right)$. No MGCs could be observed after $60 \mathrm{hr}$ at a high density $\left(6 \times 10^{5}\right.$ cells $/ \mathrm{ml})$, while at a low density $\left(3 \times 10^{5}\right.$ cells $\left./ \mathrm{ml}\right)$, small numbers of MGCs could be detected after $84 \mathrm{hr}$ (Figure $\mathbf{2 b - c}$ ). To exclude the possibility that such decrease in the number of MGCs at a higher seeding density is due to the difficulty to detect MGCs when cells are very confluent, we stained cells with a membrane dye WGA. We could not detect MGCs after $60 \mathrm{hrs}$ using confocal microscopy (Figure S8a-b). Further, we diluted the micropatterned cells with high seeding density and could not find any large cells under a hemocytometer (Figure S8c-e). These results, together with the live-cell imaging results (Figure S5 and Video S1), suggest that the decrease in the number of MGCs is likely due to the cell death. We measured the density of cells on each pattern at both plating concentrations and found that regardless of initial plating concentration, when the density on the pattern reaches $\sim 1000 \mathrm{cell} \cdot \mathrm{mm}^{-2}$, MGCs started to disappear (Figure 2d).

The heterogeneity within a cancer cell line is well-documented. To confirm that cell fusion can still happen in a population of cancer cells with a relatively uniform genetic background, we examined a subclone of HCC 1806 cells derived from a single cell (see Materials and Methods for details). Similar to parental cells, cells in this subclone can also fuse into MGCs, although the percentage of MGCs is significantly higher compared to the parental cells (Figure 2e). The fusogenicity of cells is also cell line dependent. We tested another two breast cancer cell lines BT549 and MCF-7 with different level of E-cadherin expression (see Discussion). BT549 cells 
can also fuse into MGCs similar to HCC1806 cells, while we did not observe any MGCs in MCF-7 cells in our culture condition (Figure S9). Collectively, our results clearly depicted a spontaneous fusion behavior of breast cancer cells when cultured in vitro.

\section{Allowing for dynamic invasion away from spatial pattern increases number and longevity of MGCs}

We next explored if fine-tuning cell microenvironment can preserve MGCs, which is needed for downstream cell biology studies. First, we found that changing the radius of patterns from 300 $\mu \mathrm{m}$ to $500 \mu \mathrm{m}$ can slightly increase the percentage of MGCs found in the cancer cell colonies (Figure 2f). On fixed patterns, cell density continuously increases, which may lead to the disappearance of MGCs. To allow the maintenance of cell density, we used a dynamic patterning method $^{42}$ to culture HCC1806 cells (see Methods for details). Thin PDMS stencils with a thickness between $50-100 \mu \mathrm{m}$ were generated by spin coating and arrays of through holes with an outer diameter of $1 \mathrm{~mm}$ were generated by a biopsy puncher. The PDMS stencils were placed on flat PDMS surfaces homogenously coated with fibronectin. $10 \mu 1$ of cells were directly loaded in these through holes at the concentration of $1 \times 10^{6}$ cell $\cdot \mathrm{ml}^{-1}$ to reach $\sim 100 \%$ confluency, and the stencils were removed $1 \mathrm{hr}$ after cell plating to allow the free expansion of cells (Figure 3a). Surprisingly, we found a 2.5-fold increase in the percentage of MGCs compared with fixed patterns in the first hour. More strikingly, even $84 \mathrm{hr}$ after cell plating, we found $0.8 \% \pm 0.08 \%$ of the cells were MGCs, which occupied a significant portion of cell colonies surrounded by mononuclear cells, while no MGCs can be found on fixed patterns at the same time (Figure 3bd). Of note, as we previously showed that cell packing density could influence the cell fusion, we adjusted the seeding density for the dynamic patterning condition so that the actual cell density at $12 \mathrm{hrs}$ after cell seeding is comparable between fixed and dynamic patterning 
conditions (Figure 3e). Analysis of the density of cell colonies revealed that when dynamically patterned, cancer cells maintain a density within the range of $800-1300$ cell $\cdot \mathrm{mm}^{-2}$, close to the density that promotes the formation and maintenance of MGCs (Figure 3e). As HCC1806 cells express E-cadherin, we asked if cell-cell interactions are required for cell fusion. EGTA, a calcium chelator, was used to disrupt E-cadherin mediated cell-cell junctions without significantly affecting cell adhesion ${ }^{49}$. Interestingly, EGTA significantly promoted the formation of MGCs in a dosage-dependent manner, while it failed to suppress the death of MGCs (Figure 3f). Together, these results suggest that cell-cell contact and packing density influence the formation and maintenance of MGCs. The dynamic culture system provides a convenient way for the long-term preservation of MGCs.

\section{Maintenance of MGCs depends on the ROCK-mediated cytoskeletal tension}

Given the known relationship between intracellular tension and the ability of the cell to probe the surrounding microenvironment ${ }^{50-51}$, we investigated whether cell fusion is mediated by intracellular contractile forces. We first used PDMS micropost arrays (PMAs) ${ }^{43,52}$ to measure the contractile forces of cancer cells. HCC1806 cells were seeded on PMAs homogenously coated with fibronectin $\left(50 \mu \mathrm{g} \cdot \mathrm{ml}^{-1}\right)$, and traction force of both single cells and MGCs were measured by taking a snapshot using an epifluorescence microscope (see Methods for details). The average traction force per area of MGCs is $0.14 \mathrm{nN} \cdot \mu \mathrm{m}^{-2}$, approximately 2-fold higher than that of mononuclear cells (Figure 4a-b). Notably, in MGCs, traction forces concentrated on the periphery of the entire cell, similar to the observations in single mononuclear cells. As MGCs are highly contractile, we then treated cells with Y27632 (10 $\mu \mathrm{M}$, dosed $1 \mathrm{hr}$ after cell seeding), a Rho-associated kinase (ROCK) inhibitor, to reduce cytoskeletal tensions. While it has been reported that both myoblasts fusion and cancer cell entosis processes require ROCK activity and 
cytoskeletal tensions $^{15,53}$, surprisingly, when treated with Y27632, the percentage of MGCs increased to $3.3 \% \pm 0.47 \%$ from $1.7 \% \pm 0.27 \%$ in vehicle-treated control group at $24 \mathrm{hr}$ (Figure 4c-d). This trend remained for up to $72 \mathrm{hr}$, after which most MGCs were dead in both groups. Notably, Y27632 treatment did not significantly change the cell density (Figure 4e). In addition to maintaining the MGCs, Y27632 treatment also significantly increased the size of MGCs (Figure 4f). Similarly, when cells were treated with lysophosphatidic acid, a Rho-kinase stimulator, to increase the cell traction force, the percentage of MGCs drastically decreased (Figure 4g-h). Another approach to modulate cytoskeletal tension is to change the stiffness of the underlying substrate ${ }^{54}$. To modulate the substrate stiffness, we utilized a series of PMAs with identical surface geometry but different post heights similar to our previous report ${ }^{52}$. The stiffness $K$ of these posts is solely determined by its diameter $d$ and height $L$ and by Young's modulus $E$ of PDMS, and $K$ can be approximately calculated using the Euler-Bernoulli beam theory as $K=3 \pi E d^{4} /\left(64 L^{3}\right)^{55}$. The effective Young's modulus of the substrate is determined by $E_{\text {eff }}=9 K /(2 \pi d)^{56}$. In this way, the substrate stiffness can be modulated simply by varying post height $L$ without changing the surface chemistry, topography and ligand density. Consistent with the results of ROCK inhibitor treatment, as shown in Figure 4i-j, soft substrates (Young's modulus, effective modulus $E_{\text {eff }}=5 \mathrm{kPa}$ ) led to a 3-fold increase of the percentage of MGCs at 24 hr compared with rigid substrates $\left(E_{\text {eff }}=1 \mathrm{MPa}\right)$. As cell adhesion is typically stronger on rigid substrates $^{57}$, we adjusted the initial plating concentration to ensure that the cell densities on rigid and soft substrates were comparable at $24 \mathrm{hr}$ (Figure 4k). These results suggest that the maintenance of MGCs strongly correlate with their intracellular contractile forces.

\section{Stabilizing MGCs by tuning pattern curvatures}


Several reports have demonstrated a correlation between cell adhesive pattern curvature and the contractile forces of cells ${ }^{35-36,58}$. Cells on the borders and edges of patterns typically display larger contractile forces in a curvature-dependent manner. Given our discovery of ROCKdependent MGC formation, we thus asked if the maintenance of MGCs is regulated by pattern geometry. Cells were plated on circular patterns, and the positions of MGCs were marked to generate position maps. Thereafter, multiple position maps were overplayed to generate colorimetric maps demonstrating the average distributions of MGCs. Using circular patterns, we observed that for HCC1806 cells, MGCs first appeared on the periphery of patterns within $1 \mathrm{hr}$ (Figure 5a). However, after $12 \mathrm{hr}$, MGCs started to accumulate in the center of patterns where cells are experiencing minimal stress ${ }^{35}$ (Figure 5a). We sought to investigate if this observation was due to selective proliferation of MGCs within different regions on the patterns ${ }^{58}$. As shown in Figure 5b, the cell density is homogeneous within $36 \mathrm{hr}$, indicating that in our system, cancer cell proliferation was not strongly affected by pattern geometry. Next, we asked if directed migration of MGCs contribute to their redistribution. Using live cell imaging, we found that for both the MGCs at the periphery of the pattern between $1-12 \mathrm{hr}$ and those at the center of the pattern between $25-36 \mathrm{hr}$, the radial displacements (see Figure S10 for method) of MGCs were less than 10\% (Figure 5c-h). These results suggest that directional cell migration unlikely dictates the MGCs redistribution. Collectively, our results suggest that while large cytoskeletal tension might be needed for the initiation of MGCs, their maintenance requires lower mechanical forces, consistent with results shown in Figure 4. Interestingly, for BT549 cells, which is lack of E-cadherin expression, MGCs distributed evenly across the pattern within the first $36 \mathrm{hrs,}$ suggesting that mechanosensation requires cell-cell interactions (Figure S11). Next, we designed a series of patterns with identical side lengths and different shapes. We found that MGCs 
accumulated in the center of patterns on triangular patterns while spread homogeneously on patterns with smaller curvatures (Figure 5i-I). These results suggest that MGCs avoid areas of high curvature, and areas of low tension/curvature control these cell fusion events.

\section{DISCUSSION}

The role of cell fusion in tumor progression is debatable because it is believed that only $1 \%$ of fused cells can survive and acquire new properties ${ }^{1}$. Our results demonstrate that for some breast cancer cell lines, the fusion can happen spontaneously. Importantly, our dynamic patterning system provides a convenient way to obtain MGCs using HCC1806 and BT549 breast cancer cell lines, which can be cultured stably for at least 4 days. As it has been demonstrated that MGCs are highly tumorigenic and have elevated drug resistance ${ }^{4,6-7}$, our platform has a potential to be used as a high-throughput screening tool for identifying drugs targeting MGCs. Notably, our method is considerably more physiologically relevant than existing methods to generate MGCs in vitro such as cobalt chloride treatment ${ }^{6}$. We also found that adding $0.15 \mu \mathrm{M}$ EGTA or $10 \mu \mathrm{M}$ ROCK inhibitor (Y27632) to the culture media can facilitate the formation and increase the longevity of MGCs. Contradicting effects of ROCK inhibition on tumor cell invasion and metastasis have been observed ${ }^{59}$. For example, ROCK inhibition has been demonstrated to enhance the effect of chemotherapy treatment ${ }^{60}$. However, it has also been reported that ROCK inhibition could enhance drug resistance of certain tumors ${ }^{61}$. Our findings provide additional insights in the role of Rho/ROCK signaling in cancer biology. Of note, the MGCs obtained using the dynamic patterning can be passaged using standard 
Trypsin/EDTA-based cell dissociation method, and MGCs can still be found after replated to a new tissue culture plate.

The fusogenicity of breast cancer cells are not directly correlated with the epithelialmesenchymal transition, because cell fusion has been observed in both HCC1806 (E-cadherin positive) and BT549 (E-cadherin negative) cell lines, but not in MCF-7 (E-cadherin positive) cell line. Thus, it will be intriguing to investigate if fusogenicity is a unique characteristic of cancer cells implicating their metastatic potentials.

Overholtzer and co-workers have identified a mechanosensitive, nonapoptotic cell death process, termed entosis, that leads to ploidy increase in human cancers ${ }^{48,53,62}$. During entosis, a host cell can internalize another cell in a Rho-GTPase and Rho-kinase-dependent manner, leading to a cell-in-cell structure. While we cannot completely rule out the possibility of entosis in our study, we did not observe cell-in-cell structures in our phalloidin staining images, and many MGCs can successfully divide into two or more cells, in contrast to undergoing cytokinesis failure during entosis. In addition, inhibition of Rho-kinase activity increases the percentage of MGCs. These results collectively suggest that entosis is unlikely a dominant mechanism in our system. It is possible that in tumors, entosis and cell fusion can independently contribute to the polyploidy formation in cancer cells.

Cell-cell fusion occurs spontaneously in several normal developmental processes ${ }^{10-12}$ and can be induced in tissue culture using fusogens such as polyethylene glycol ${ }^{3}$ and viruses ${ }^{63}$. Doxorubicin and cobalt chloride have been shown to induce chemoresistant, stem-cell like polyploid cells through cell fusion ${ }^{6,64}$, suggesting a strong connection between cancer cell fusion and cancer progression ${ }^{4,65}$. Ogle and co-workers reported that hypoxia and apoptotic 
conditions promote cancer cell fusion ${ }^{66}$. However, the molecular mechanism of cancer cell fusion is poorly understood. Activation of ELMO/Dock180/Rac1 signaling has been shown to be involved in the fusion of myoblasts and macrophages ${ }^{10,13-14}$. However, this pathway is unlikely to be involved in our system because Rac1 is known to be deactivated on softer substrates $^{67}$, which support more MGCs in our study compared with stiffer substrates. A recent study highlighted the role of mechanical tension in Drosophila myoblast fusion ${ }^{15}$. It has been found that Rho-myosin mediates the enrichment of actomyosin network in the receiving cells, which provides reactive forces to the protrusive forces generated by the attacking cell, and such reactive forces are required for successful fusion. Figure 6 illustrated the major differences between the myoblast fusion and breast cancer cell fusion processes. Based on these findings, we reason that the larger number of MGCs presented in low intracellular force conditions might be mainly due to increased survival rate rather than the elevated chance of fusion events (Figure S12). Our results suggest dynamically controlled actomyosin activities might be needed for maximizing the fusogenicity of cancer cells.

Together, the governing mechanisms of cancer cell fusion are underexplored, and future work is needed to reveal further the molecular pathways involved in this process, as well as to validate these mechanisms in vivo. 


\section{FIGURES AND CAPTIONS}

\section{Figure 1}

a

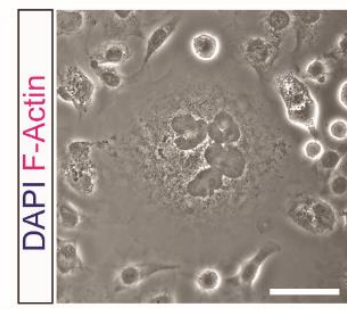

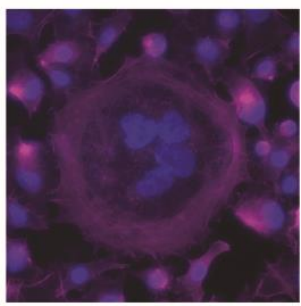

d

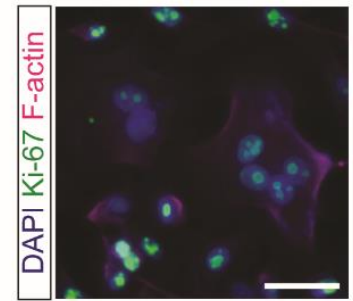

$24 \mathrm{hr}$

f

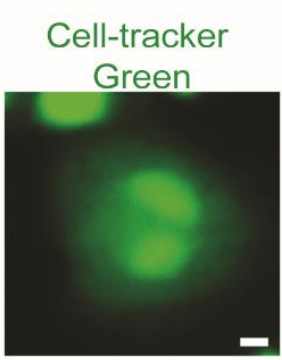

e

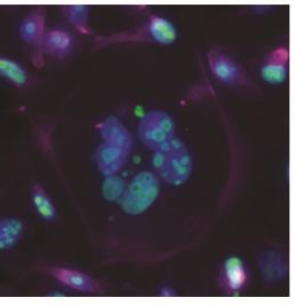

$72 \mathrm{hr}$

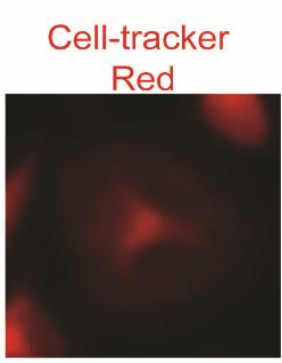

b

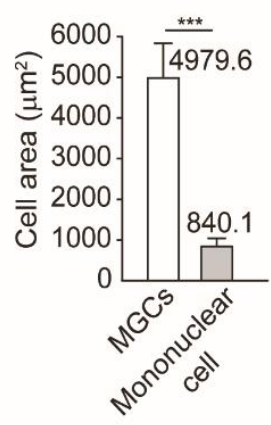

C

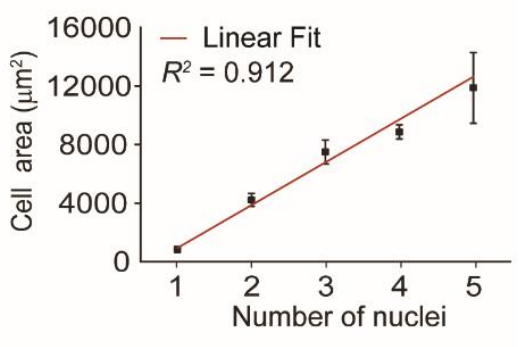

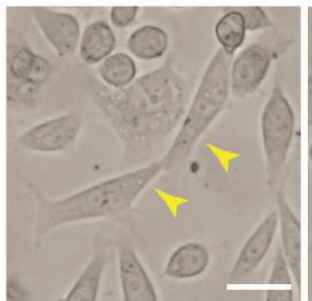

$\mathrm{t}$ (mins) 0

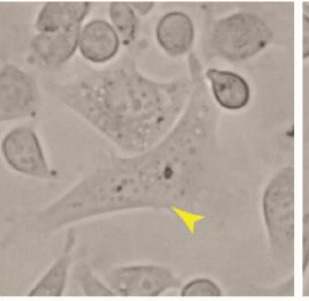

30

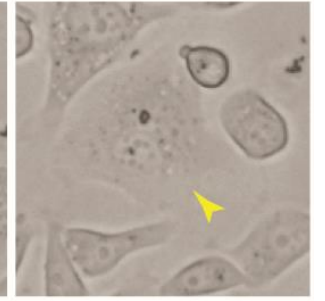

60
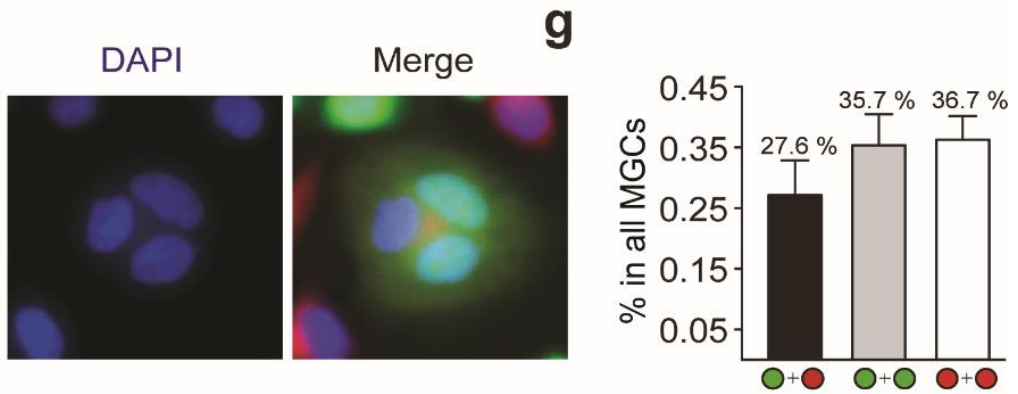

Figure 1. MGCs formed mainly through cell fusion. (a) Representative phase contrast (left) and immunofluorescence (right) images showing MGCs. Cells were stained with Phalloidin (pink) and DAPI (blue). Scale bar, $50 \mu \mathrm{m}$. (b) Bar plot showing the area of MGCs and mononuclear cell $24 \mathrm{hr}$ after cell seeding. Data represent mean \pm s.e.m. 20 and 25 cells were analyzed for MGCs and mononuclear cells, respectively. ***, $P<0.001$. (c) Bar plot showing the cell area as a function of the number of nuclei in each cell, and the result of linear fitting. (d) Representative immunofluorescence images showing MGCs cells at 24 and $72 \mathrm{hr}$ after cell seeding. Cells were fixed and stained for F-actin (Phalloidin, pink), Nuclear (DAPI, blue), and Ki-67 (green). Scale bar, $25 \mu \mathrm{m}$. (e) Representative live-cell, bright field images showing dynamics of the fusion of two mononuclear cells. Arrowheads mark mononuclear cells and fused cell. Scale bar, $25 \mu \mathrm{m}$. (f) Representative immunofluorescence images are showing the fusion of two cells labeled with cell-tracker green and cell-tracker red, respectively. Scale bar, $10 \mu \mathrm{m} .(\mathrm{g})$ Bar plot showing the percentage of MGCs labeled with either cell-track green, cell-track red, or both. Cell line: HCC 1806. 
Figure 2

a

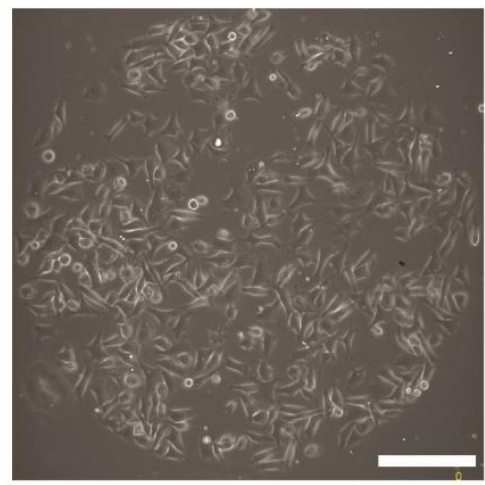

$1 \mathrm{hr}$

b

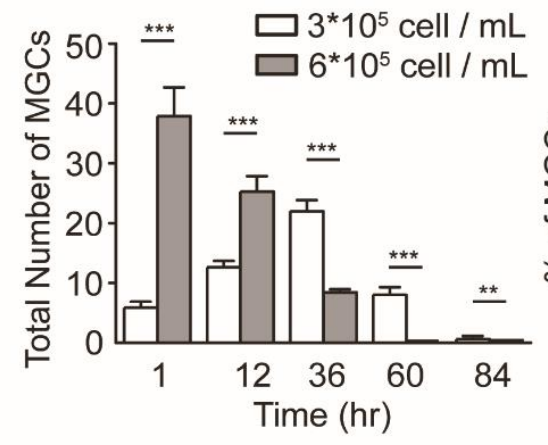

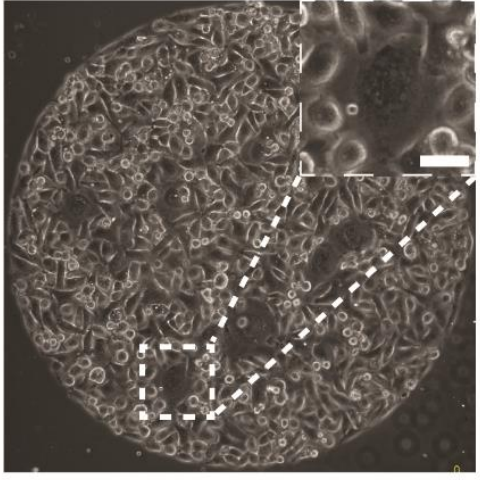

$36 \mathrm{hr}$

C

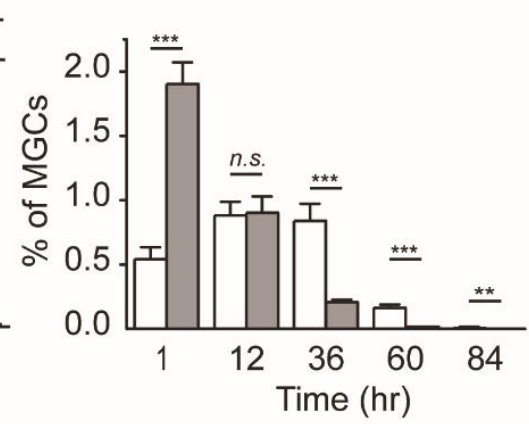

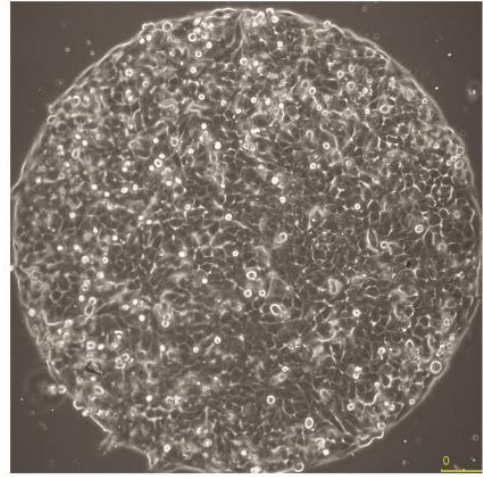

$84 \mathrm{hr}$

d

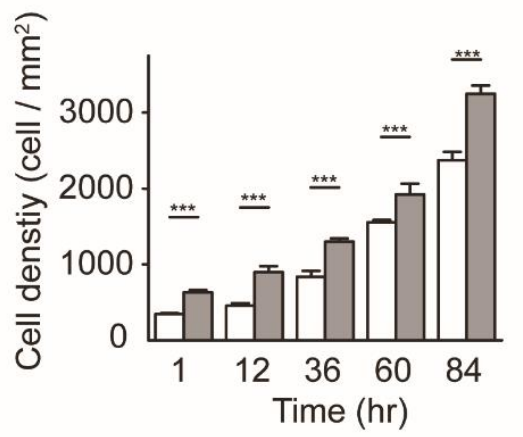

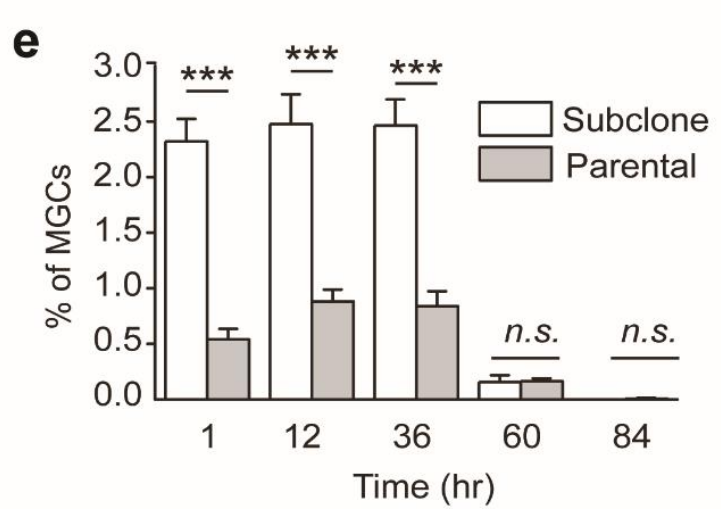

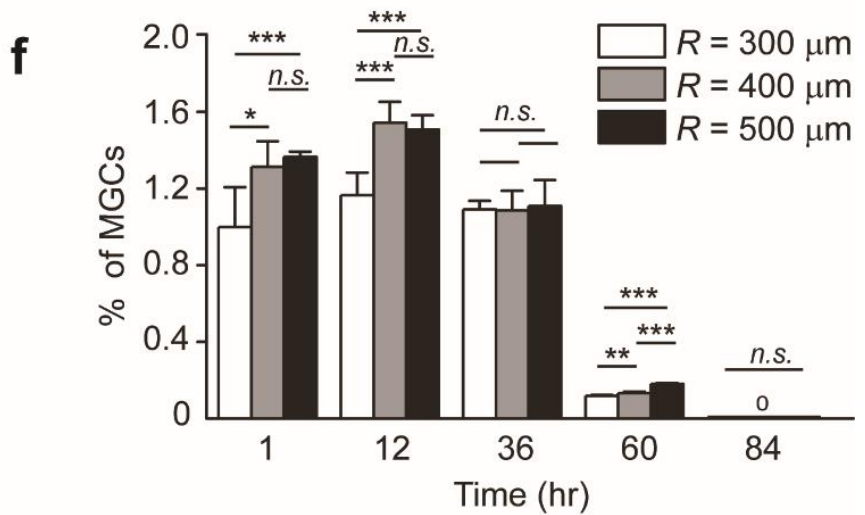

Figure 2. Regulation of fusogenicity of breast cancer cells. (a) Phase contrast images showing HCC1806 breast cancer cells cultured on patterned surfaces with fixed pattern size (radius $r=$ $500 \mu \mathrm{m}$ ) for 1, 36, and $84 \mathrm{hrs}$ on flat PDMS substrates. Scale bar, $100 \mu \mathrm{m}$, and $20 \mu \mathrm{m}$ (insert). (b-c) Bar plots showing the total number (b) and percentage of MGCs (c) with initial seeding concentrations of $3 \times 10^{5}$ cell $\cdot \mathrm{ml}^{-1}$ and $6 \times 10^{5}$ cell $\cdot \mathrm{ml}^{-1}$, respectively (d) Cell density on each pattern as functions of time and initial seeding density. (e) Bar plot showing the percentage of 
MGCs cells using cells either from the original HCC1806 cell line or a subclone of HCC1806 cell line obtained from a single cell. (f) Bar plot showing the effects of pattern size $(r=300,400$, $500 \mu \mathrm{m})$ on the percentage of MGCs at different time points as indicated. Cells were plated at $5 \times 10^{5}$ cell. $\mathrm{ml}^{-1}$. Data represent mean \pm s.e.m from at least three independent experiments. ${ }^{*}, P<$ $0.05, * *, P<0.01, * * *, P<0.001$, n.s.,$P>0.05$. Cell line: HCC 1806. 
Figure 3

a
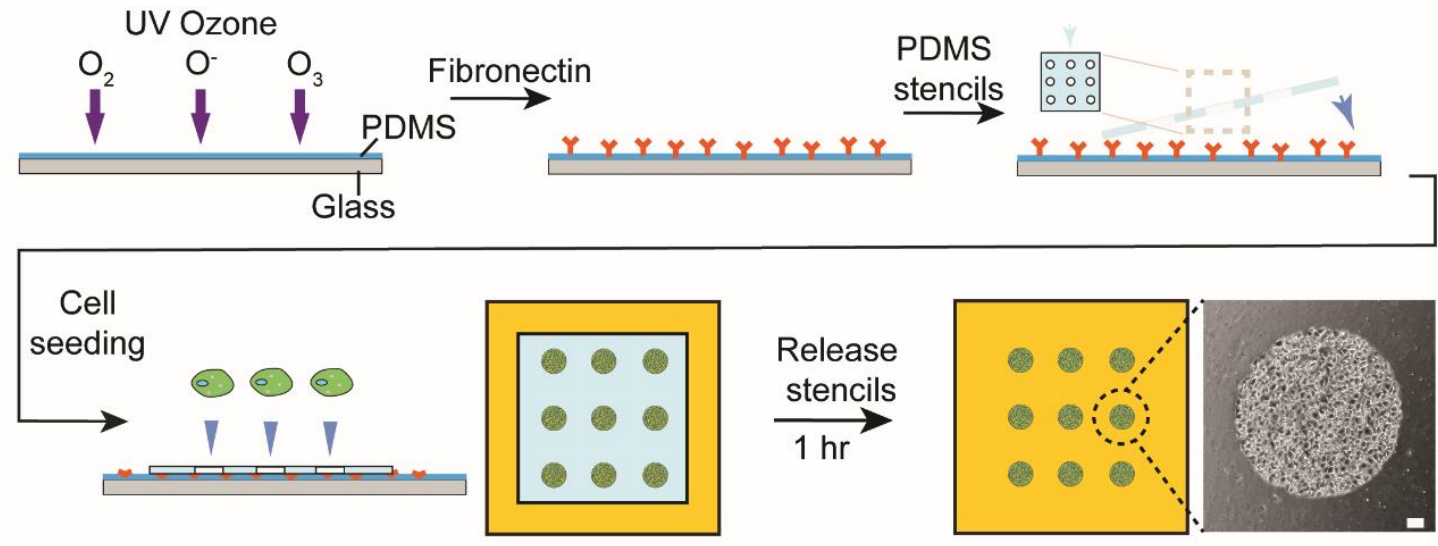

b
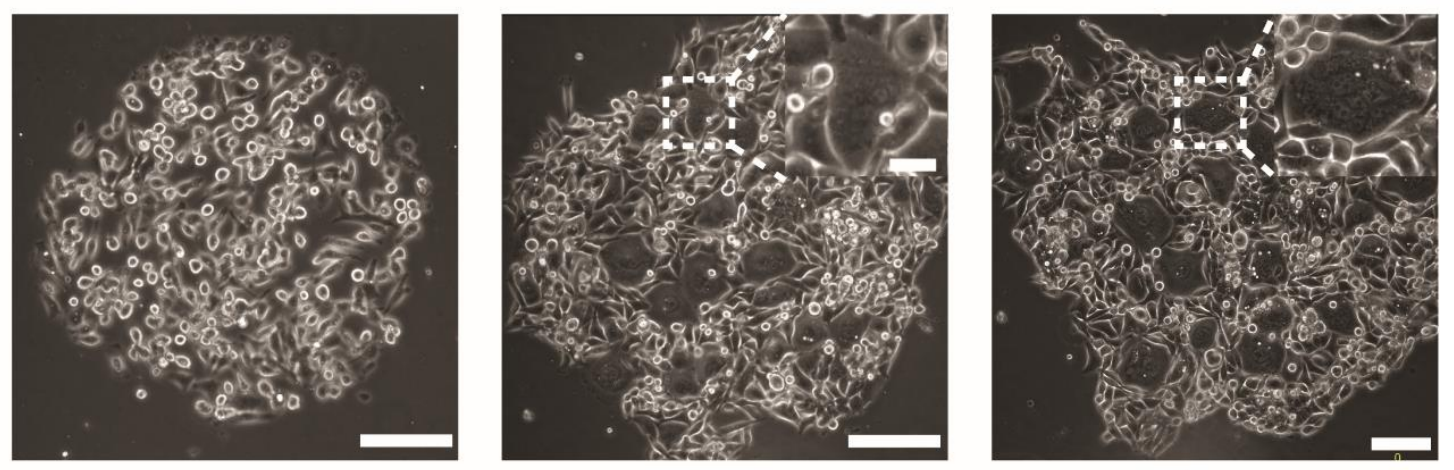

$1 \mathrm{hr}$

c

d

$36 \mathrm{hr}$
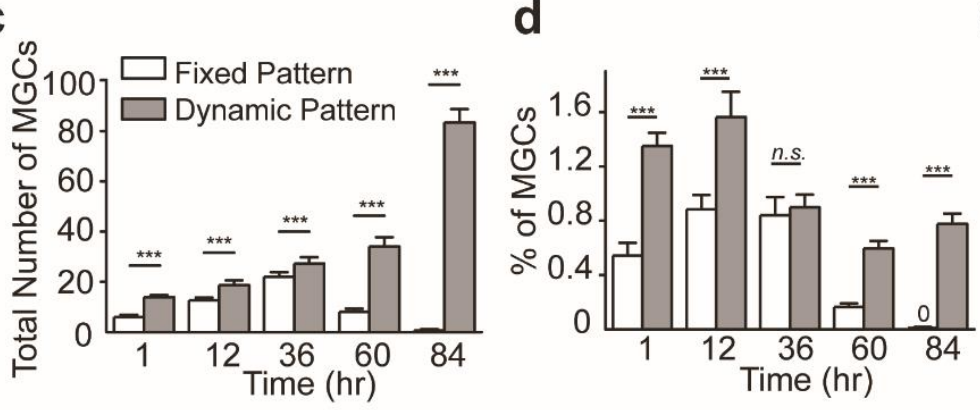

e

$84 \mathrm{hr}$

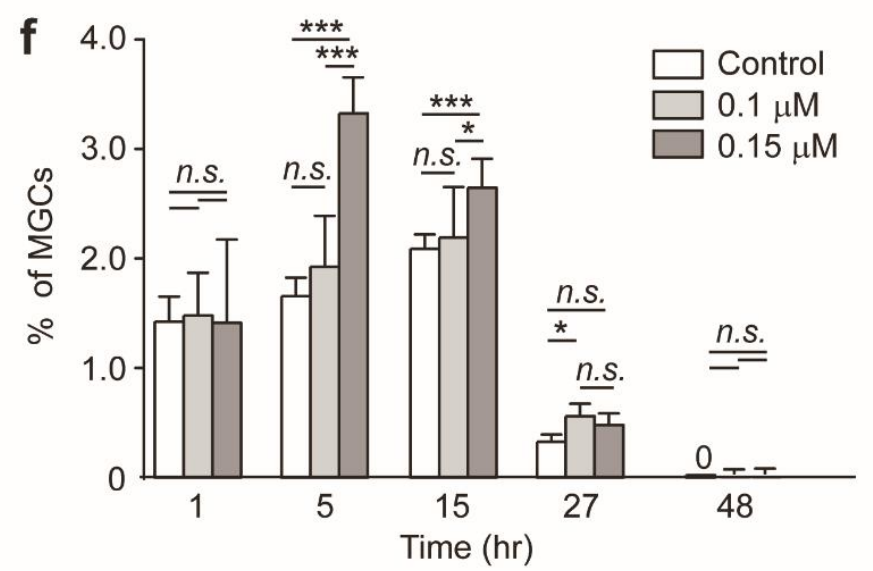


Figure 3. Dynamically patterned culture increases number and longevity of MGCs. (a) Schematic diagram showing the process of dynamic patterning. PDMS stencils were used as masks to pattern cells on PDMS surface uniformly coated with fibronectin. Phase contrast image shows a representative image of patterned cells $1 \mathrm{hr}$ after cell seeding. Scale bar, $100 \mu \mathrm{m}$. (b) Phase contrast images showing HCC1806 breast cancer cells cultured on flat PDMS substrates for 1, 36, and $84 \mathrm{hrs}$. PDMS stencils were used to generate confluent colonies of cells with defined initial geometry (radius $r=500 \mu \mathrm{m}$ ). Scale bar, $100 \mu \mathrm{m}$, and $20 \mu \mathrm{m}$ (insert). (c-d) Bar plots showing the total number (c) and percentage of MGCs (d) on either fixed or dynamic patterns with initial seeding concentrations of $3 \times 10^{5} \mathrm{cell} \cdot \mathrm{ml}^{-1}$ (fixed) or $1 \times 10^{6} \mathrm{cell} \cdot \mathrm{ml}^{-1}$ (dynamic). (e) Bar plots showing the density of cells on either fixed or dynamic patterns. (f) Bar plots showing the effect of EGTA treatment $(0.1 \mathrm{mM}$ or $0.15 \mathrm{mM}$, cells treated $1 \mathrm{hr}$ after cell seeding) on the percentage of MGCs at different time points as indicated. Cells were cultured on patterned PDMS surface (circular patterns, radius $r=500 \mu \mathrm{m}$ ). Data represent mean \pm s.e.m from at least three independent experiments. ${ }^{*}, P<0.05$, **, $P<0.01$, ***, $P<0.001$, n.s., $P>$ 0.05. Cell line: HCC 1806. 
Figure 4
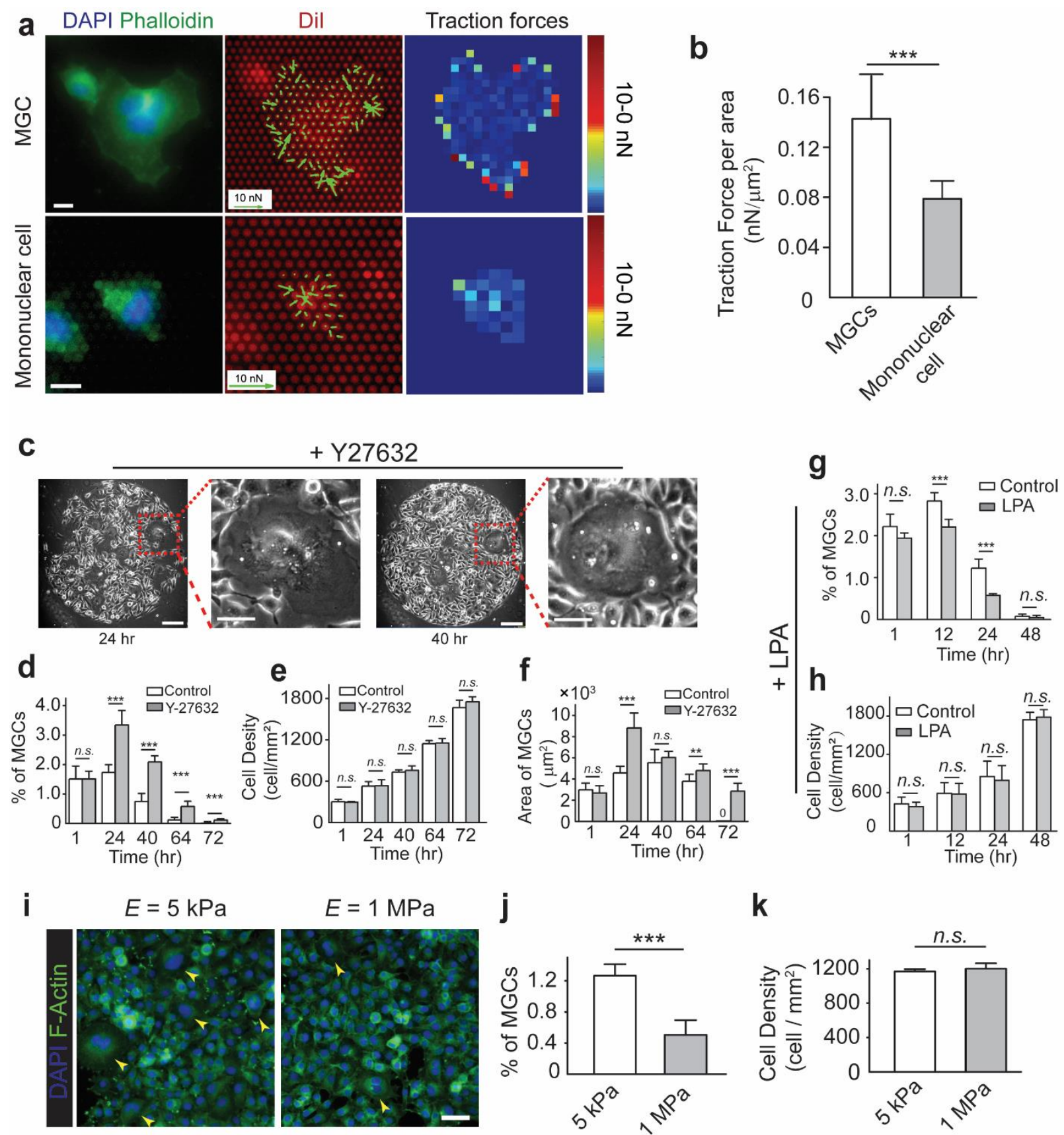

Figure 4. Biomechanical regulation of cell fusion and MGCs maintenance. (a) Representative immunofluorescence images showing an MGC (top panel) and a mononuclear cell (bottom panel) on PMA substrates. Left: cells stained with DAPI (blue) and Phalloidin. Middle: Microposts labeled with DiI (red) and vector map of traction forces (green); Right: Colorimetric map of traction forces. Scale bar, $10 \mu \mathrm{m}$. (b) Bar plot showing the traction force per area of MGCs and mononuclear cells. (c) Representative phase contrast images showing MGCs $24 \mathrm{hr}$ and $40 \mathrm{hr}$ after cell seeding in the presence of Y-27632 $(10 \mu \mathrm{M})$. Y-27632 was dissolved in 
DMSO and added to the cell culture media $1 \mathrm{hr}$ after cell seeding. Scale bar, $200 \mu \mathrm{m}$ and $50 \mu \mathrm{m}$ (insert). (d-f) Bar plots showing the percentage (d), cell density (e), and the cell area (f) of MGCs in colonies treated with DMSO (control) and Y27632. (g-h) Bar plots showing the percentage (g) of MGCs and cell density (h) after exposed to $10 \mu \mathrm{M}$ LPA. (i) Representative immunofluorescence images showing cells cultured on PMA substrates with different effective Young's moduli. Arrowheads indicate MGCs. Scale bar, $25 \mu \mathrm{m}$. (j-k) Bar plots showing the percentage of MGCs (j) and cell density (k) on soft and rigid substrates, respectively. Data represents mean \pm s.e.m. **, $P<0.01$, ***, $P<0.001$, n.s., $P>0.05$. Cell line: HCC 1806. 
Figure 5

a
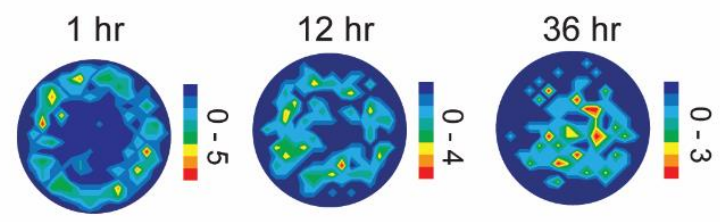

b
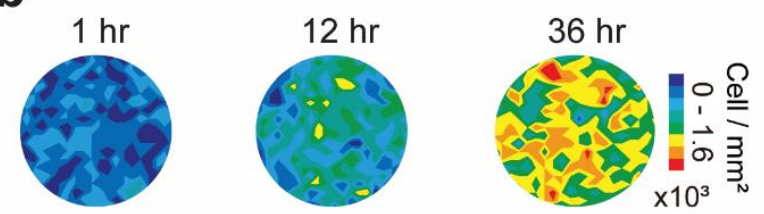

$1-12 \mathrm{hr}$

C

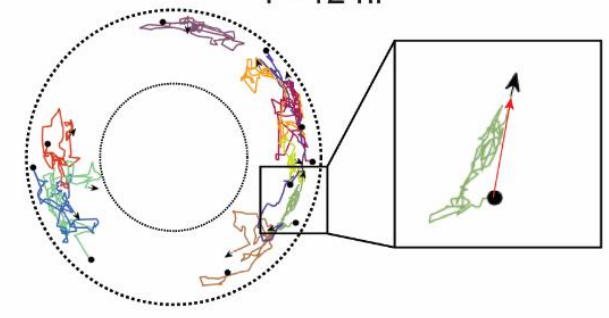

d

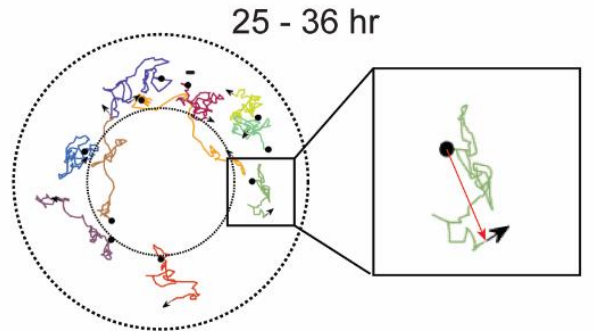

e

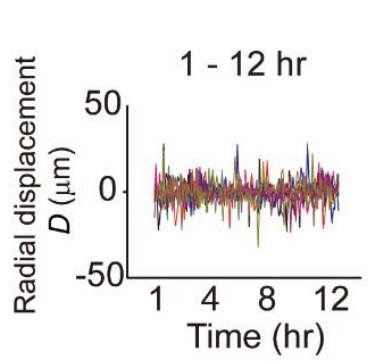

g

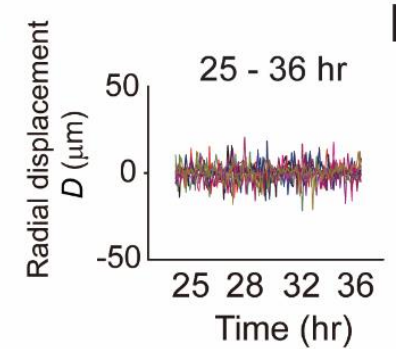

i
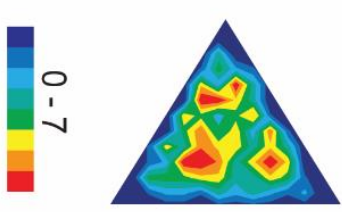

$\mathbf{k}$

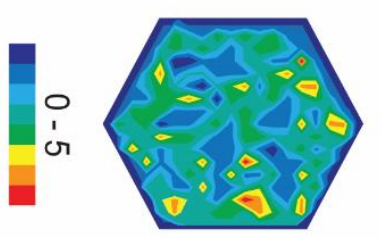

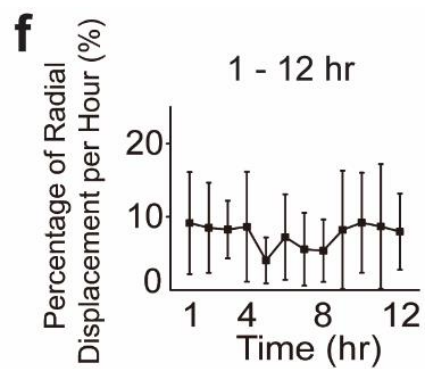

h

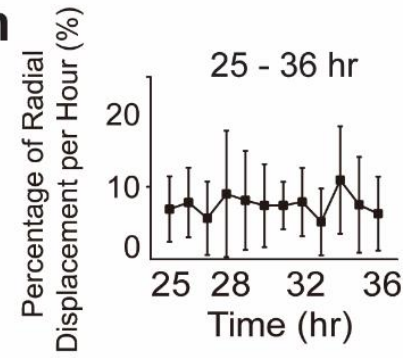

j

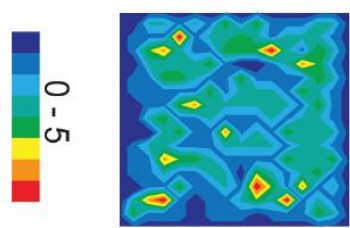

I
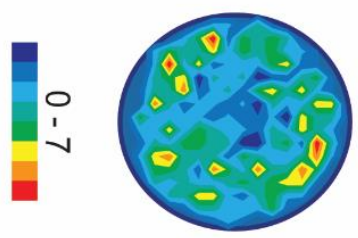

Figure 5. Pattern curvature regulates MGCs distribution. (a) Colorimetric maps showing the distribution of MGCs on circular patterns at $1 \mathrm{hr}, 12 \mathrm{hr}$, and $36 \mathrm{hr}$ as indicated. The radius of the circular pattern is $400 \mu \mathrm{m}$. (b) Colorimetric maps showing the cell density on circular patterns at $1 \mathrm{hr}, 12 \mathrm{hr}$, and $36 \mathrm{hr}$. The radius of the circular pattern is $400 \mu \mathrm{m}$. (c-d) Schematic diagrams showing the migration trajectories of MGCs. Circular dots mark original positions, and arrowheads mark final positions. (e-h) Plots showing radial displacements and percentages of radial displacements per hour between 1-12 hr (e-f) and 25-36 hr (g-h). (i-l) Colorimetric maps showing the distribution of MGCs on the triangle (i), square (j), hexagon (k), and circular (l) patterns with identical side width of $600 \mu \mathrm{m}$. The results were obtained by overlapping the distribution of MGCs at 1, 12 and $24 \mathrm{hr}$ after cell seeding. Number of MGCs in each grid is color coded. Cell line: HCC 1806. 


\section{Figure 6}
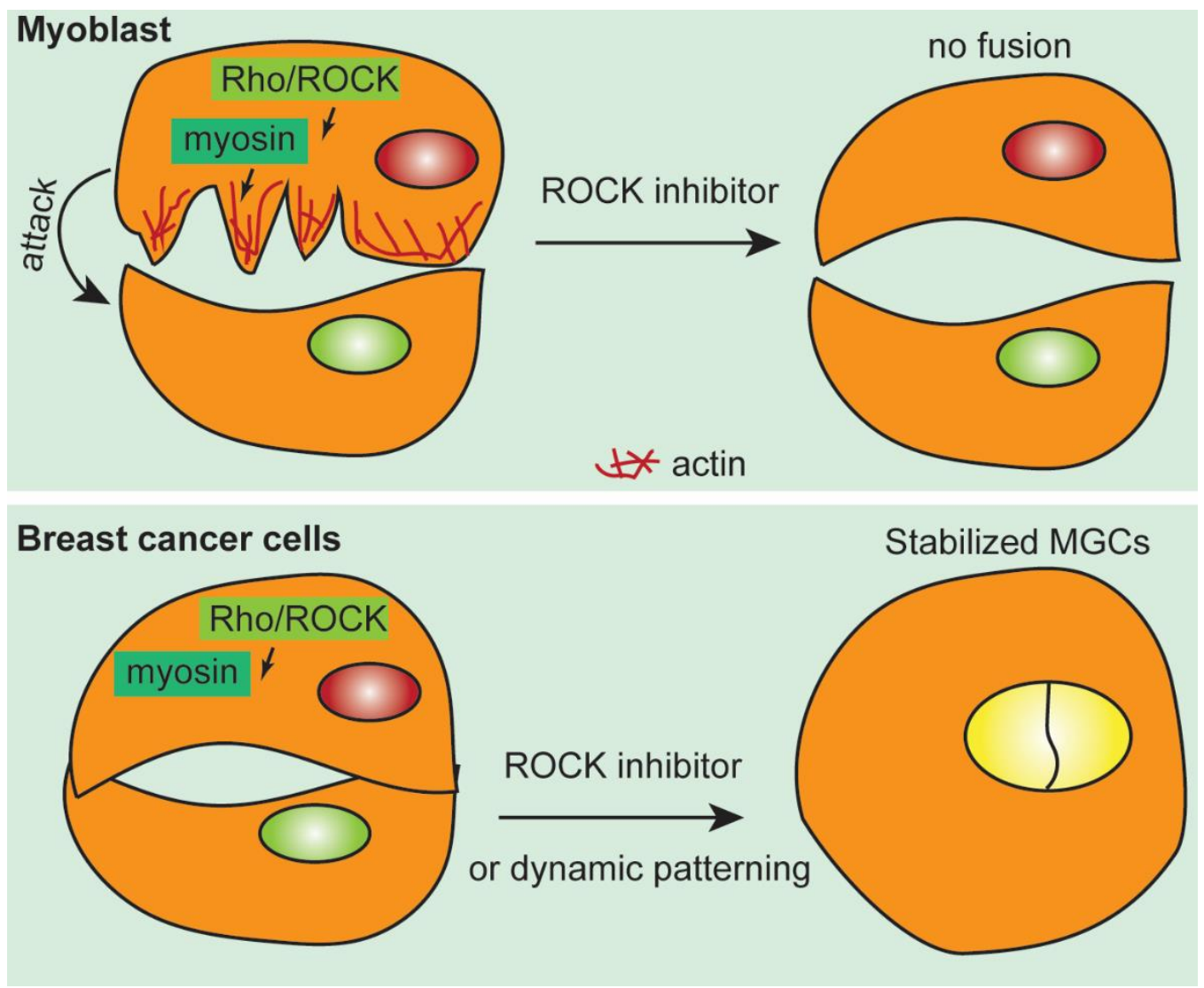

Figure 6. Rho-ROCK signaling in the cell fusion process. A schematic image showing different role of Rho-ROCK signaling in the cell fusion of myoblast (top) and breast cancer cells (bottom). ROCK inhibition attenuated the chance of cell fusion in myoblast while facilitated the fusion of breast cancer cells and stabilized MGCs. 


\section{SUPPORTING INFORMATION}

Figure S1 provides MGCs found in cells cultured on glass substrates; Figure S2 provides representative bright field images showing MGCs dividing into 3 mononuclear cells; Figure S3 provides the frequency of cell fusion and cytokinesis failure; Figure S4 shows the baseline of MGCs in the HCC 1806 cell line; Figure S5 provides representative bright field images showing the fate of MGCs tracked on a fixed pattern by live-cell imaging; Figure S6 provides representative bright field images showing the fusion of two MGCs.; Figure S7 provides a schematic of fixed patterns; Figure S8 provides the disappearance of MGCs at high cell density; Figure S9 provides MGCs found in BT549 cells but not in MCF7 cells; Figure S10 provides a schematic diagram showing the method of radial displacement calculation; Figure S11 provides distribution of MGCs on circular patterns using cell line BT549. Figure S12 describes the relationship among cell density, fusion of MGCs and MGC death under fixed or dynamic pattern conditions.

Supporting video provides video-microscopy showing the fate of MGCs, including cell fusion, division, cytokinesis failure, and cell death. Cell grown on the same pattern (radius $r=200 \mu \mathrm{m}$ ) was tracked for $66 \mathrm{hr}$.

\section{AUTHOR INFORMATION}

\section{Corresponding Author}

*Correspondence should be addressed to Y. Sun (ybsun@umass.edu)

\section{Author Contributions}


P.Z., S.P., and Y.S. designed experiments; P.Z. and N.T. performed experiments; T.X. fabricated molds for PDMS stencils; N. Li analyzed traction forces of cells; P.Z., N.T., I.F., S. P., and Y.S. analyzed data; P.Z. and Y.S. wrote the manuscript. All authors edited and approved the final manuscript.

The authors declare no competing financial interest.

\section{ACKNOWLEDGMENT}

This work is supported in part by the National Science Foundation (CMMI 1662835 to Y.S.) and the Department of Mechanical and Industrial Engineering at the University of Massachusetts Amherst. The Conte Nanotechnology Cleanroom Lab is acknowledged for support in microfabrication. 


\section{REFERENCE}

1. Wakeling, W. F.; Greetham, J.; Bennett, D. C., Efficient Spontaneous Fusion Between Some Co-cultured Cells, Especially Murine Melanoma Cells. Cell Biology International 1994, 18 (3), 207-210.

2. Fortuna, M. B.; Dewey, M. J.; Furmanski, P., Enhanced lung colonization and tumorigenicity of fused cells isolated from primary MCA tumors. Cancer Lett 1990, 55 (2), 10914.

3. Barski, G.; Cornefert, F. R., Characteristics of "Hybrid"-Type Clonal Cell Lines Obtained From Mixed Cultures In Vitro2. JNCI: Journal of the National Cancer Institute 1962, 28 (4), 801-821.

4. Duelli, D.; Lazebnik, Y., Cell fusion: a hidden enemy? Cancer Cell 2003, 3 (5), 445-8.

5. Douglas-Jones, A. G.; Barr, W. T., Breast carcinoma with tumor giant cells. Report of a case with fine needle aspiration cytology. Acta Cytol 1989, 33 (1), 109-14.

6. Z Zhang, S.; Mercado-Uribe, I.; Xing, Z.; Sun, B.; Kuang, J.; Liu, J., Generation of cancer stem-like cells through the formation of polyploid giant cancer cells. Oncogene 2014, 33 (1), 116-128.

7. Zhang, W. H.; Lin, Q. T.; Ramoth, A. J.; Fan, D.; Fidler, I. J., Formation of Solid Tumors by a Single Multinucleated Cancer Cell. Cancer 2011, 117 (17), 4092-4099.

8. Lu, X.; Kang, Y., Efficient acquisition of dual metastasis organotropism to bone and lung through stable spontaneous fusion between MDA-MB-231 variants. Proc Natl Acad Sci U S A 2009, 106 (23), 9385-90.

9. Noubissi, F. K.; Ogle, B. M., Cancer Cell Fusion: Mechanisms Slowly Unravel. Int J Mol Sci 2016, 17 (9).

10. $\quad$ Aguilar, P. S.; Baylies, M. K.; Fleissner, A.; Helming, L.; Inoue, N.; Podbilewicz, B.; Wang, H.; Wong, M., Genetic basis of cell-cell fusion mechanisms. Trends Genet 2013, 29 (7), 427-37.

11. Chen, E. H.; Olson, E. N., Unveiling the mechanisms of cell-cell fusion. Science 2005, 308 (5720), 369-73.

12. Sapir, A.; Avinoam, O.; Podbilewicz, B.; Chernomordik, L. V., Viral and developmental cell fusion mechanisms: conservation and divergence. Dev Cell 2008, 14 (1), 11-21.

13. Hochreiter-Hufford, A. E.; Lee, C. S.; Kinchen, J. M.; Sokolowski, J. D.; Arandjelovic, S.; Call, J. A.; Klibanov, A. L.; Yan, Z.; Mandell, J. W.; Ravichandran, K. S., Phosphatidylserine receptor BAI1 and apoptotic cells as new promoters of myoblast fusion. Nature 2013, 497 (7448), 263-+.

14. Pajcini, K. V.; Pomerantz, J. H.; Alkan, O.; Doyonnas, R.; Blau, H. M., Myoblasts and macrophages share molecular components that contribute to cell-cell fusion. Journal of Cell Biology 2008, 180 (5), 1005-1019.

15. Kim, J. H.; Ren, Y. X.; Ng, W. P.; Li, S.; Son, S. M.; Kee, Y. S.; Zhang, S. L.; Zhang, G. F.; Fletcher, D. A.; Robinson, D. N.; Chen, E. H., Mechanical Tension Drives Cell Membrane Fusion. Developmental Cell 2015, 32 (5), 561-573.

16. Duda, D. G.; Duyverman, A. M.; Kohno, M.; Snuderl, M.; Steller, E. J.; Fukumura, D.; Jain, R. K., Malignant cells facilitate lung metastasis by bringing their own soil. P Natl Acad Sci USA 2010, 107 (50), 21677-82. 
17. Huwart, L.; Salameh, N.; ter Beek, L.; Vicaut, E.; Peeters, F.; Sinkus, R.; Van Beers, B. E., MR elastography of liver fibrosis: preliminary results comparing spin-echo and echo-planar imaging. Eur Radiol 2008, 18 (11), 2535-41.

18. Huwart, L.; Peeters, F.; Sinkus, R.; Annet, L.; Salameh, N.; ter Beek, L. C.; Horsmans, Y.; Van Beers, B. E., Liver fibrosis: non-invasive assessment with MR elastography. NMR Biomed 2006, 19 (2), 173-9.

19. Tilghman, R. W.; Cowan, C. R.; Mih, J. D.; Koryakina, Y.; Gioeli, D.; Slack-Davis, J. K.; Blackman, B. R.; Tschumperlin, D. J.; Parsons, J. T., Matrix rigidity regulates cancer cell growth and cellular phenotype. PLoS One 2010, 5 (9), e12905.

20. Paszek, M. J.; Zahir, N.; Johnson, K. R.; Lakins, J. N.; Rozenberg, G. I.; Gefen, A.;

Reinhart-King, C. A.; Margulies, S. S.; Dembo, M.; Boettiger, D.; Hammer, D. A.; Weaver, V. M., Tensional homeostasis and the malignant phenotype. Cancer Cell 2005, 8 (3), 241-254.

21. Paszek, M. J.; Weaver, V. M., The tension mounts: mechanics meets morphogenesis and malignancy. J Mammary Gland Biol Neoplasia 2004, 9 (4), 325-42.

22. Levental, K. R.; Yu, H.; Kass, L.; Lakins, J. N.; Egeblad, M.; Erler, J. T.; Fong, S. F.; Csiszar, K.; Giaccia, A.; Weninger, W.; Yamauchi, M.; Gasser, D. L.; Weaver, V. M., Matrix crosslinking forces tumor progression by enhancing integrin signaling. Cell 2009, 139 (5), 891906.

23. Matsuzaki, K., Modulation of TGF-beta signaling during progression of chronic liver diseases. Front Biosci 2009, 14, 2923-34.

24. Wynn, T. A., Cellular and molecular mechanisms of fibrosis. J Pathol 2008, 214 (2), 199-210.

25. Saile, B.; Ramadori, G., Inflammation, damage repair and liver fibrosis--role of cytokines and different cell types. Z Gastroenterol 2007, 45 (1), 77-86.

26. Bretscher, M. S., On the shape of migrating cells--a 'front-to-back' model. J Cell Sci 2008, 121 (Pt 16), 2625-2628.

27. Iwanicki, M. P.; Davidowitz, R. A.; NG, M. R.; Besser, A.; Muranen, T.; Merritt, M.; Danuser, G.; Ince, T.; Brugge, J., Ovarian cancer spheroids use myosin-generated force to clear the mesothelium. Cancer Discov 2011, 1, 144-157.

28. Provenzano, P. P.; Eliceiri, K. W.; Campbell, J. M.; Inman, D. R.; White, J. G.; Keely, P. J., Collagen reorganization at the tumor-stromal interface facilitates local invasion. BMC Med 2006, 4 (1), 38 .

29. Kostic, A.; Lynch, C. D.; Sheetz, M. P., Differential matrix rigidity response in breast cancer cell lines correlates with the tissue tropism. PLoS One 2009, 4 (7), e6361.

30. Dumont, N.; Liu, B.; Defilippis, R. A.; Chang, H.; Rabban, J. T.; Karnezis, A. N.; Tjoe, J. A.; Marx, J.; Parvin, B.; Tlsty, T. D., Breast fibroblasts modulate early dissemination, tumorigenesis, and metastasis through alteration of extracellular matrix characteristics.

Neoplasia 2013, 15 (3), 249-62.

31. Sanz-Moreno, V.; Gaggioli, C.; Yeo, M.; Albrengues, J.; Wallberg, F.; Viros, A.; Hooper, S.; Mitter, R.; Feral, C. C.; Cook, M.; Larkin, J.; Marais, R.; Meneguzzi, G.; Sahai, E.; Marshall, C. J., ROCK and JAK1 signaling cooperate to control actomyosin contractility in tumor cells and stroma. Cancer Cell 2011, 20 (2), 229-45.

32. Pathak, A.; Kumar, S., Independent regulation of tumor cell migration by matrix stiffness and confinement. Proc Natl Acad Sci U S A 2012, 109 (26), 10334-9.

33. Shen, K.; Luk, S.; Hicks, D. F.; Elman, J. S.; Bohr, S.; Iwamoto, Y.; Murray, R.; Pena, K.; Wang, F.; Seker, E.; Weissleder, R.; Yarmush, M. L.; Toner, M.; Sgroi, D.; Parekkadan, B., 
Resolving cancer-stroma interfacial signalling and interventions with micropatterned tumourstromal assays. Nat Commun 2014, 5, 5662.

34. Ingber, D. E., Mechanical control of tissue growth: function follows form. Proc Natl Acad Sci U S A 2005, 102 (33), 11571-2.

35. Nelson, C. M.; Jean, R. P.; Tan, J. L.; Liu, W. F.; Sniadecki, N. J.; Spector, A. A.; Chen, C. S., Emergent patterns of growth controlled by multicellular form and mechanics. Proc Natl Acad Sci U S A 2005, 102 (33), 11594-9.

36. Lee, J.; Abdeen, A. A.; Wycislo, K. L.; Fan, T. M.; Kilian, K. A., Interfacial geometry dictates cancer cell tumorigenicity. Nat. Mater. 2016, 15 (8), 856-+.

37. Nguyen, T. V.; Sleiman, M.; Moriarty, T.; Herrick, W. G.; Peyton, S. R., Sorafenib resistance and JNK signaling in carcinoma during extracellular matrix stiffening. Biomaterials 2014, 35 (22), 5749-5759.

38. Carey, S. P.; Kraning-Rush, C. M.; Williams, R. M.; Reinhart-King, C. A., Biophysical control of invasive tumor cell behavior by extracellular matrix microarchitecture. Biomaterials 2012, 33 (16), 4157-4165.

39. Suresh, S., Biomechanics and biophysics of cancer cells. Acta Biomater. 2007, 3 (4), 413438.

40. Jain, R. K.; Martin, J. D.; Stylianopoulos, T., The Role of Mechanical Forces in Tumor Growth and Therapy. Annual Review of Biomedical Engineering, Vol 16 2014, 16, 321-346.

41. Lam, R. H. W.; Sun, Y. B.; Chen, W. Q.; Fu, J. P., Elastomeric microposts integrated into microfluidics for flow-mediated endothelial mechanotransduction analysis. Lab Chip 2012, 12 (10), 1865-1873.

42. Xue, X.; Sun, Y.; Resto-Irizarry, A. M.; Yuan, Y.; Aw Yong, K. M.; Zheng, Y.; Weng, S.; Shao, Y.; Chai, Y.; Studer, L.; Fu, J., Mechanics-guided embryonic patterning of neuroectoderm tissue from human pluripotent stem cells. Nat. Mater. 2018.

43. Fu, J. P.; Wang, Y. K.; Yang, M. T.; Desai, R. A.; Yu, X. A.; Liu, Z. J.; Chen, C. S., Mechanical regulation of cell function with geometrically modulated elastomeric substrates. Nat. Meth. 2010, 7 (9), 733-736.

44. Weng, S.; Shao, Y.; Chen, W.; Fu, J., Mechanosensitive subcellular rheostasis drives emergent single-cell mechanical homeostasis. Nat Mater 2016.

45. Chen, C. S.; Mrksich, M.; Huang, S.; Whitesides, G. M.; Ingber, D. E., Micropatterned surfaces for control of cell shape, position, and function. Biotechnol. Prog. 1998, 14 (3), 356-363. 46. Kwon, M.; Godinho, S. A.; Chandhok, N. S.; Ganem, N. J.; Azioune, A.; Thery, M.; Pellman, D., Mechanisms to suppress multipolar divisions in cancer cells with extra centrosomes. Genes Dev 2008, 22 (16), 2189-203.

47. Krajcovic, M.; Overholtzer, M., Mechanisms of Ploidy Increase in Human Cancers: A New Role for Cell Cannibalism. Cancer Research 2012, 72 (7), 1596-1601.

48. Overholtzer, M.; Mailleux, A. A.; Mouneimne, G.; Normand, G.; Schnitt, S. J.; King, R. W.; Cibas, E. S.; Brugge, J. S., A Nonapoptotic Cell Death Process, Entosis, that Occurs by Cellin-Cell Invasion. Cell 2007, 131 (5), 966-979.

49. Ohgushi, M.; Matsumura, M.; Eiraku, M.; Murakami, K.; Aramaki, T.; Nishiyama, A.; Muguruma, K.; Nakano, T.; Suga, H.; Ueno, M.; Ishizaki, T.; Suemori, H.; Narumiya, S.; Niwa, H.; Sasai, Y., Molecular Pathway and Cell State Responsible for Dissociation-Induced Apoptosis in Human Pluripotent Stem Cells. Cell Stem Cell 2010, 7 (2), 225-239.

50. $\quad$ Swift, J.; Ivanovska, I. L.; Buxboim, A.; Harada, T.; Dingal, P. C. D. P.; Pinter, J.; Pajerowski, J. D.; Spinler, K. R.; Shin, J.-W.; Tewari, M.; Rehfeldt, F.; Speicher, D. W.; Discher, 
D. E., Nuclear Lamin-A Scales with Tissue Stiffness and Enhances Matrix-Directed Differentiation. Science 2013, 341 (6149).

51. Sun, Y.; Chen, C. S.; Fu, J., Forcing stem cells to behave: a biophysical perspective of the cellular microenvironment. Annual Review of Biophysics 2012, 41, 519-42.

52. $\quad$ Sun, Y.; Yong, K. M. A.; Villa-Diaz, L. G.; Zhang, X.; Chen, W.; Philson, R.; Weng, S.;

$\mathrm{Xu}, \mathrm{H}$.; Krebsbach, P. H.; Fu, J., Hippo/YAP-mediated rigidity-dependent motor neuron differentiation of human pluripotent stem cells. Nat. Mater. 2014, 13 (6), 599-604.

53. Hamann, J. C.; Surcel, A.; Chen, R.; Teragawa, C.; Albeck, J. G.; Robinson, D. N.;

Overholtzer, M., Entosis Is Induced by Glucose Starvation. Cell Reports 2017, 20 (1), 201-210.

54. Ingber, D. E., Cellular mechanotransduction: putting all the pieces together again. Faseb J 2006, 20 (7), 811-827.

55. Tan, J. L.; Tien, J.; Pirone, D. M.; Gray, D. S.; Bhadriraju, K.; Chen, C. S., Cells lying on a bed of microneedles: An approach to isolate mechanical force. Proceedings of the National Academy of Sciences of the United States of America 2003, 100 (4), 1484-1489.

56. Saez, A.; Buguin, A.; Silberzan, P.; Ladoux, B., Is the mechanical activity of epithelial cells controlled by deformations or forces? Biophys. J. 2005, 89 (6), L52-L54.

57. Discher, D. E.; Janmey, P.; Wang, Y.-1., Tissue cells feel and respond to the stiffness of their substrate. Science 2005, 310 (5751), 1139-1143.

58. Ruiz, S. A.; Chen, C. S., Emergence of Patterned Stem Cell Differentiation Within Multicellular Structures. Stem Cells 2008, 26 (11), 2921-2927.

59. Wei, L.; Surma, M.; Shi, S.; Lambert-Cheatham, N.; Shi, J., Novel Insights into the Roles of Rho Kinase in Cancer. Archivum immunologiae et therapiae experimentalis 2016, 64 (4), 259278.

60. Ohta, T.; Takahashi, T.; Shibuya, T.; Amita, M.; Henmi, N.; Takahashi, K.; Kurachi, H., Inhibition of the Rho/ROCK pathway enhances the efficacy of cisplatin through the blockage of hypoxia-inducible factor- $1 \alpha$ in human ovarian cancer cells. Cancer Biology \& Therapy 2012, 13 (1), 25-33.

61. Street, C. A.; Routhier, A. A.; Spencer, C.; Perkins, A. L.; Masterjohn, K.; Hackathorn, A.; Montalvo, J.; Dennstedt, E. A.; Bryan, B. A., Pharmacological inhibition of Rho-kinase (ROCK) signaling enhances cisplatin resistance in neuroblastoma cells. Int J Oncol 2010, 37 (5), 1297-305.

62. Durgan, J.; Tseng, Y.-Y.; Hamann, J. C.; Domart, M.-C.; Collinson, L.; Hall, A.; Overholtzer, M.; Florey, O., Mitosis can drive cell cannibalism through entosis. eLife 2017, 6, e27134.

63. Martin, I.; Ruysschaert, J. M., Common properties of fusion peptides from diverse systems. Bioscience Rep 2000, 20 (6), 483-500.

64. Yang, J. Y.; Ha, S. A.; Yang, Y. S.; Kim, J. W., p-Glycoprotein ABCB5 and YB-1 expression plays a role in increased heterogeneity of breast cancer cells: correlations with cell fusion and doxorubicin resistance. Bmc Cancer 2010, 10.

65. Rachkovsky, M.; Sodi, S.; Chakraborty, A.; Avissar, Y.; Bolognia, J.; McNiff, J. M.; Platt, J.; Bermudes, D.; Pawelek, J., Melanoma x macrophage hybrids with enhanced metastatic potential. Clin Exp Metastasis 1998, 16 (4), 299-312.

66. Noubissi, F. K.; Harkness, T.; Alexander, C. M.; Ogle, B. M., Apoptosis-induced cancer cell fusion: a mechanism of breast cancer metastasis. Faseb Journal 2015, 29 (9), 4036-4045. 
67. Pasapera, A. M.; Plotnikov, S. V.; Fischer, R. S.; Case, L. B.; Egelhoff, T. T.; Waterman, C. M., Rac1-Dependent Phosphorylation and Focal Adhesion Recruitment of Myosin IIA Regulates Migration and Mechanosensing. Curr. Biol. 2015, 25 (2), 175-186. 


\section{For Table of Contents Use Only}

\section{Biomechanical microenvironment regulates fusogenicity of breast cancer cells}

Peiran Zhu ${ }^{1}$, Ning-Hsuan Tseng ${ }^{2}$, Tianfa Xie ${ }^{1}$, Ningwei Li ${ }^{1}$, Isaac Fitts-Sprague ${ }^{1}$, Shelly R. Peyton $^{2,3,4}$, and Yubing Sun ${ }^{1,2,3,4^{*}}$

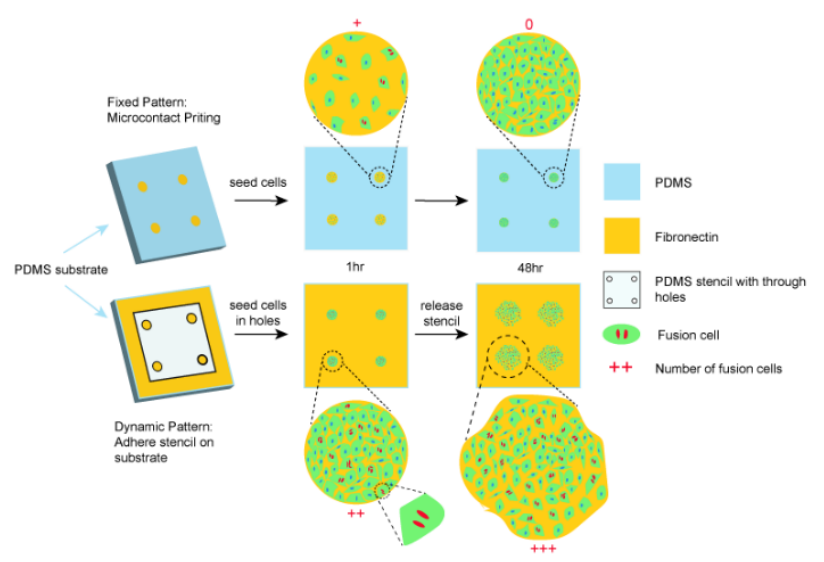

